\title{
Mapping of performance of pumped thermal energy storage (Carnot battery) using waste heat recovery
}

\author{
O. Dumont*, V. Lemort \\ Thermodynamics Laboratory, University of Liège, 4000, Liège, Belgium
}

\section{A R T I C L E I N F O}

\section{Article history:}

Received 21 January 2020

Received in revised form

8 September 2020

Accepted 27 September 2020

Available online 5 October 2020

\section{Keywords:}

Carnot battery

Pumped thermal energy storage

Mapping

Waste heat recovery

Cartography

Electrical storage

\begin{abstract}
A B S T R A C T
The growth of renewable energy requires flexible, low-cost and efficient electrical storage to balance the mismatch between energy supply and demand. Pumped thermal energy storage (PTES or Carnot battery) converts electric energy to thermal energy with a heat pump (or another heating system) when electricity production is greater than demand; when electricity demand outstrips production the PTES generates power from two thermal storage reservoirs (possibly a Rankine cycle mode). Classical PTES architectures do not achieve more than $60 \%$ roundtrip electric efficiency. However, innovative architectures, using waste heat recovery (thermally integrated PTES) are able to reach electrical power production of the power cycle larger than the electrical power consumption of the heat pump, increasing the value of the technology. In this paper, a general model is developed to draw mappings of performance depending on the two main inputs (waste heat and ambient air temperatures). Whatever the storage configurations, the best performances are reached when the waste heat temperature is high, the air temperature is low, and the lift of the heat pump is low. Finally, the thermally integrated PTES technology is compared with other technologies of energy storages and is theoretically promising due to its high roundtrip efficiency, its low specific price and no specific geographical conditions.
\end{abstract}

(C) 2020 Elsevier Ltd. All rights reserved.

\section{Introduction}

\subsection{Context}

The share of renewable energy production is expected to grow significantly in the next decades. In this context, due to the variability of the wind and solar energy, energy storage solutions are required to provide electricity when required. In this context, the Pumped Thermal Energy Storage (PTES), or Carnot battery, is a promising technology to store electricity. Basically, a heating cycle provides heat to a hot storage by using excess electricity (charge) while a power cycle converts this stored thermal energy into electricity when required (discharge) (Fig. 1). Several demonstrators are being built around the world [1-4]. Different technologies and architectures are possible for this technology. This paper focuses on PTES using waste heat recovery (Thermally Integrated Pumped Thermal Energy Storage - TIPTES) combined with a reversible Heat Pump/Organic Rankine Cycle (HP/RC).

\footnotetext{
* Corresponding author.

E-mail address: olivier.dumont@ulg.ac.be (O. Dumont).
}

Different types of PTES have been proposed in the literature:

- Depending on the required temperature levels, the power cycle can be, among other possibilities, a Brayton cycle, a Rankine cycle [5], a trans-critical $\mathrm{CO}_{2}$ cycle or a Lamm-Honigmann process [6]. The competitive technology, the closed Brayton cycle, despite promising efficiencies, requires very high temperature levels $\left(>320^{\circ} \mathrm{C}\right)$ [7] which may lead to high components and TES costs. Moreover, in a power cycle, high temperatures usually demonstrate higher efficiencies, but as will be demonstrated in this paper (section 3, the thermally integrated PTES (TIPTES) technology is more efficient at low temperatures.

- The PTES can be composed of a separate heat pump and power cycle or can be a sole unit able to provide both modes with the same components (reversible HP/ORC system) [8-10]. The technical feasibility of such a system has been demonstrated experimentally [11].

- If available, waste heat may be used as the heat source of the heat pump to increase its coefficient of performance [12,13] or as a heat source of the power cycle, resulting in a thermally integrated PTES (TIPTES). 


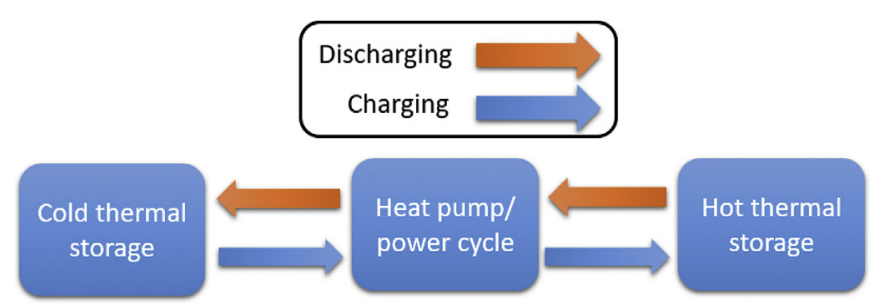

Fig. 1. Heat flow of a classical Pumped Thermal Energy Storage.

- The heat pump cycle can be used to produce thermal energy that, once stored, permits to produce electricity through a power cycle (hot storage layout). But, another possibility is to produce cold thermal energy (chiller system), store it, and use it to increase the efficiency of the power cycle through a lower condensation temperature (cold storage layout) [14].

- The energy can be stored under latent or sensible energy [5].

\subsection{Thermally integrated pumped thermal energy storage}

Typically, the power to power ratio (P2P), defined as the electrical energy output (discharge) divided by the electrical energy input (charge) is below 70\% for classical PTES. This is the reason why it can be helpful to valorize waste heat fluxes in the system to improve its performance (TIPTES). Some authors expect more than $100 \%$ P2P [12,13]. Compared to a classical PTES using a hot and a cold storage, there are two different options to operate a TIPTES (Fig. 2). On the one hand, the hot storage configuration uses a heating system (heat pump in this example) to increase the waste heat temperature. This allows the power cycle ( $R C$ in this example) to increase its performance by working with a higher temperature difference. On the other hand, the cold storage configuration stores thermal energy at temperatures lower than the ambient (through a vapor cycle in this example). Once again, it allows the power cycle to work efficiently with a higher temperature difference.

\subsection{Reversible heat pump/organic Rankine cycle}

The PTES unit can be a sole unit able to provide both modes with the same components (reversible HP/RC system) [8-15]. Indeed, heat pumps and RC power systems present many similarities for low and mid-scale systems (working fluids, compressors, heat exchangers among others). The technical feasibility of such a system has been demonstrated experimentally by the authors [15]. This solution presents the advantages to be cheaper, more compact and easier to operate compared to two separate systems. In those systems, the Reynolds ratio (Eq. (1)), defined as the ratio between the highest Reynolds number of the RC divided by the highest one of the HP, needs to be constrained [15]. In Eq. (1), the Reynolds is defined at the exhaust of the expander in RC mode and at the inlet of the compressor in HP mode. This is why areas $(A)$ and lengths $(L)$ are equal in both modes (see Eq. (1))

$R e_{\text {ratio }}=\frac{\operatorname{Re}_{R C}}{R e_{H P}}=\frac{\frac{S_{O C} L_{R C}}{v_{R C}}}{\frac{S_{H P} L_{H P}}{v_{H P}}}=\frac{\frac{\dot{m}_{R C} L_{R C}}{A_{R C} \rho_{R C} v_{R C}}}{\frac{\dot{m}_{H P} L_{H P}}{A_{H P} \rho_{H P} v_{H P}}}=\frac{\frac{\dot{m}_{R C}}{\rho_{R C} v_{R C}}}{\frac{\dot{m}_{H P}}{\rho_{H P} v_{H P}}}$

If not constrained, heat exchangers performance, the efficiency of the expander and compressor, the pressure drops and the oil circulation rate will be affected. Moreover, it influences directly the charge and discharge times. The ratio of the charge time to the discharge time is roughly equal to the Reynolds ratio. As an example, the discharge time is three times smaller than the charging time with a Reynolds ratio of 3 .

The aim of this paper is to investigate the cold and hot storage configurations of thermally integrated PTES due to their high potential. In the methodology section, the modeling equations and hypotheses are presented. Following this, the results section provides mappings of performance to understand optimal working conditions of these systems by varying the most influent parameters. Also, the energy density of such systems is assessed. In the conclusion, a comparison with competitive technologies of energy storages is analyzed.

\section{Methodology}

The idea of this paper is to provide a general model to simulate the two aforementioned systems in a wide range of operating conditions. No detailed technological considerations are thus taken into account to obtain a general formalism. The mappings are only provided to give trends and to understand the potential of the technology. It is important to note that a more detailed model should be used in the case of the design or part load simulation of such a unit. However, it is well known that constant efficiency models are realistic in the nominal sizing conditions of the machine. This type of modeling is therefore consistent for the purpose of this paper, which is to derive global mappings without entering into technical details to obtain general guidelines for the technology. In this analysis, the influence of the size (power) of the system is not taken into account. In practice, the expander and compressor efficiency are slightly increasing by using larger power. Also, volumetric machines are usually preferred to turbomachinery for low scale power machines ( tens of $\mathrm{kW}$ ). However this differentiation is not considered here since the only parameter related to the compressor or the expander is its isentropic efficiency. Only the heat pump/Rankine cycle combination is considered in this paper.

\subsection{Heat pump and power cycle}

The heat flow charts for the hot and cold storage configurations are provided in Fig. 3. Here, the considered system is a reversible heat pump/Rankine Cycle unit (HP/RC) but two separate systems for each operating mode can also be considered [9]. For the cold storage layout, the charging process utilizes electricity to run the
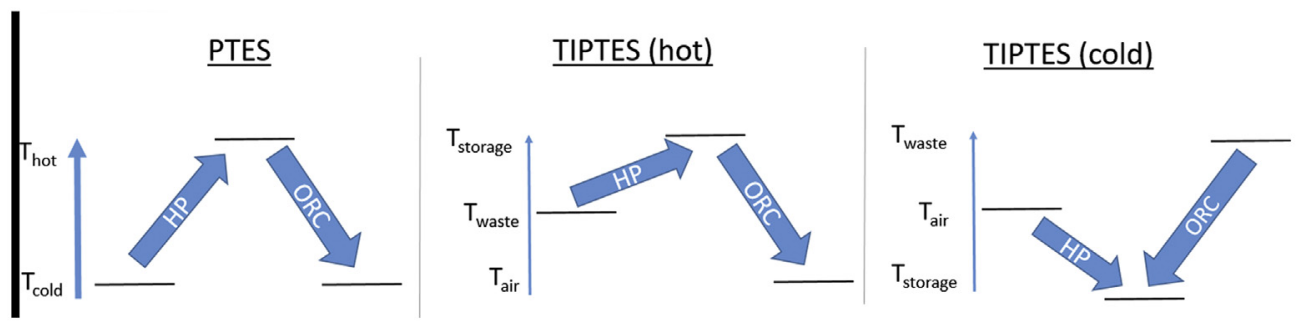

Fig. 2. PTES (left), PTES with hot storage (center) and PTES with cold storage (right). 

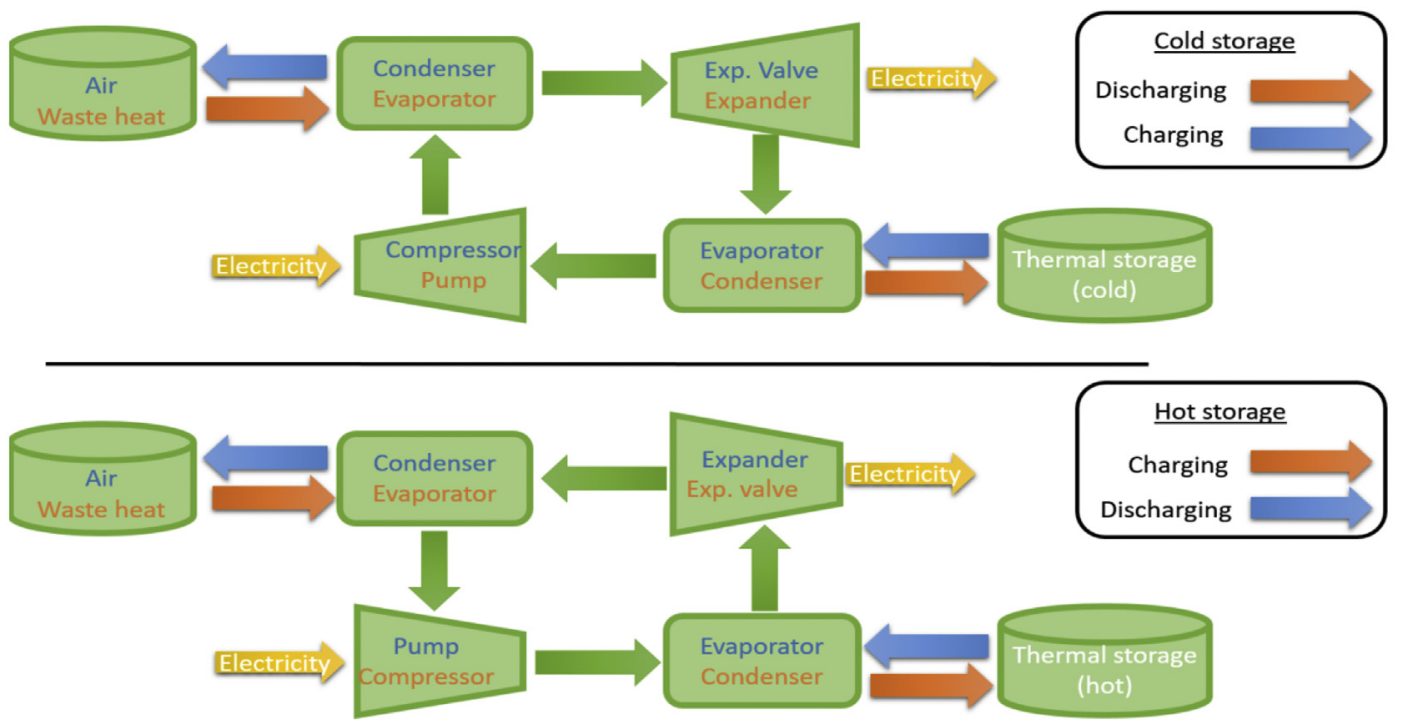

Fig. 3. Heat flow chart for the hot and cold storage configurations.

compressor of the heat pump. From there, the condenser releases thermal energy in the air. Following this, the working fluid enters the expansion valve and reaches the low pressure and temperature level. The evaporator retrieves thermal energy from the cold TES. During the discharge process, the pump provides a given flow of refrigerant that is sent to the evaporator. The waste heat source evaporates the working fluid and electricity is produced in the expander. The cold TES is the heat sink of the power cycle. In the case of the hot storage configuration, the charging process starts with the compressor of the heat pump, which increases the temperature and pressure level of the working fluid. The thermal energy is provided to the hot storage through the condenser. Then, the working fluid flows through the expansion valve to reach the low temperature and pressure side. The waste heat source is used to transform the working fluid into vapor in the evaporator. The discharge process uses the temperature difference between the hot storage and the air to run the expander and produce electricity.

The modeling of the heat pump and the power cycle, assumed to be a Rankine cycle (RC) in this case, is performed based on constant efficiencies and pinch points modeling. For a given configuration, the HP and the RC utilize the same working fluid for the sake of simplicity. The temperature glide $\Delta T$ corresponds to the temperature difference of the secondary fluids between the inlet and outlet of the heat exchangers. This temperature glide also corresponds to the temperature difference between the hot and cold parts of the thermal storages. For more clarity, T-s diagrams are shown in Fig. 4. In these diagrams, the RC (green) is always operated between the highest temperature difference for high efficiency (red and blue curve) while the HP operates with a small lift as it is beneficial for the COP and the P2P (as proven in section 3).

\subsection{Analytical model}

This analytical model is very general and is based on the comparison with an ideal Carnot cycle. $\Delta T$ is defined as the lift of the heat pump. The lift is defined as the difference between the waste heat temperature and the storage temperature for the hot configuration and as the difference between the air and the storage temperature for the cold configuration (Fig. 1).

The heat pump coefficient of performance (COP) in heating mode is defined by Eq. (2) while the one in cooling mode is defined by Eq. (3) [8]. They correspond to the COP of a Carnot system multiplied by a factor $(g)$ taking into account all the irreversibilities and physical constraints.

$C O P_{\text {heating }}=\frac{Q_{c d}}{E_{e l}}=g_{\text {heating }} \frac{T_{\text {hot }}}{T_{\text {hot }}-T_{\text {cold }}}$
$\operatorname{COP}_{\text {cooling }}=\frac{Q_{e v}}{E_{e l}}=g_{\text {cooling }} \frac{T_{\text {cold }}}{T_{\text {hot }}-T_{\text {cold }}}$

The Rankine cycle (RC) efficiency is defined by the Carnot efficiency multiplied by a factor $(g)$ taking into account all the irreversibilities and physical constraints (Eq. (4) [8]).

$\eta_{R C}=\frac{E_{e l}}{Q_{e v}}=g_{R C}\left(1-\frac{T_{\text {cold }}}{T_{\text {hot }}}\right)$

It is conventionally accepted that $g$ is comprised between 0.5 and 0.7 to obtain performance that match real applications [8]. In the case of the hot storage architecture, the P2P is simply evaluated by the product of the COP and the efficiency of the power cycle (Eq. (5)) in which $Q_{e v}$ is the thermal energy at the evaporator.

$P 2 P_{h o t}=\left(\frac{C O P_{H P, h o t}}{Q_{c d, H P}}\right) \cdot\left(\eta_{R C, h o t} Q_{e v, R C}\right)=C O P_{H P, h o t} \cdot \eta_{R C, h o t}$

In the case of the cold storage, the P2P is defined by Eq (6) where $Q_{c d}$ is the thermal energy at the condenser.

$P 2 P_{\text {cold }}=\frac{E_{e l, o u t}}{E_{e l, \text { in }}}=\left(\frac{C O P_{H P, \text { cold }}}{Q_{e v, H P}}\right) \cdot\left(\eta_{R C, \text { cold }} Q_{e v, R C}\right)=\frac{\eta_{R C, \text { cold }}}{1-\eta_{R C, \text { cold }}} C O P_{H P, \text { cold }}$ 

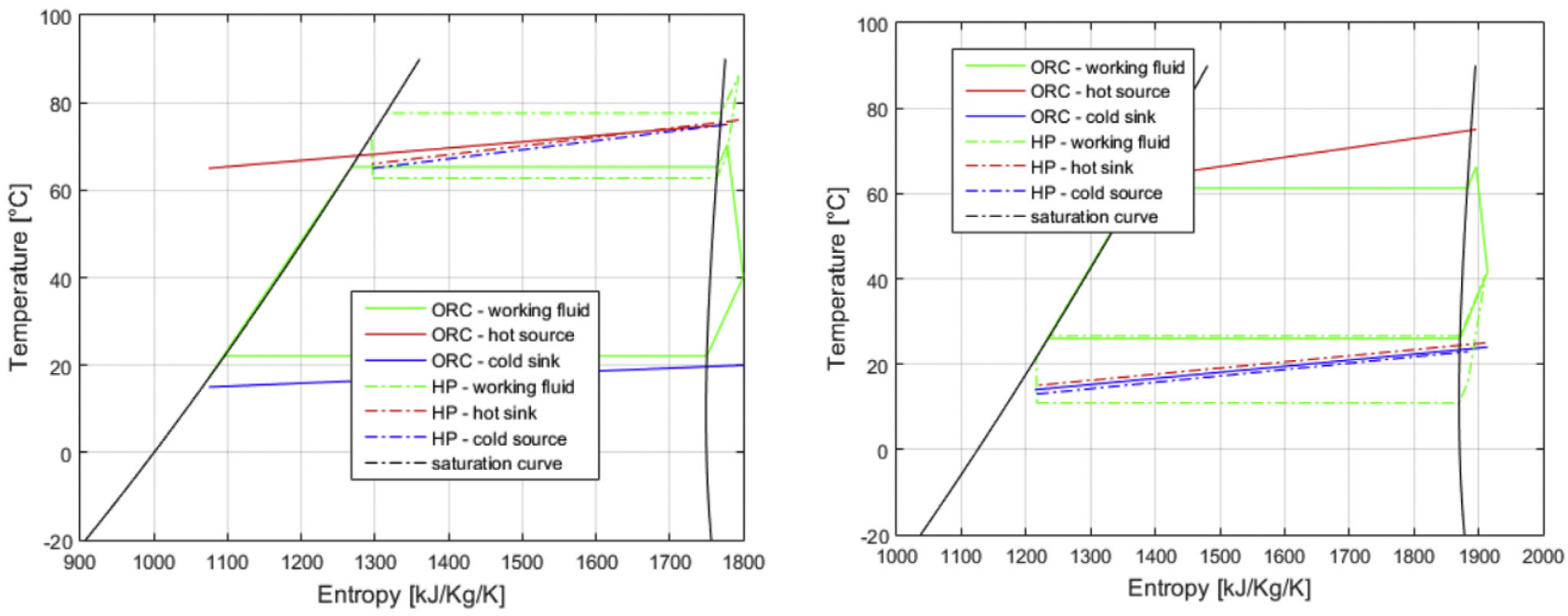

Fig. 4. Example of T-s diagram for the hot configuration (left) and cold configuration (right).

A simple analytical model based on Eqs. (2)-(6) provides the ratio of the P2P between the cold and hot storage layouts (Eq. (11)). The demonstration is provided through (Eqs. (7)-(11)). For the simplicity of the formulation, $g$ is assumed to be equal in Eqs. (7)-(11).

$R=\frac{P 2 P_{\text {cold }}}{P 2 P_{\text {hot }}}=\frac{\eta_{R C, \text { cold }}}{1-\eta_{R C, \text { cold }}} C O P_{H P, \text { cold }} \cdot \frac{1}{\mathrm{COP}_{H P, \text { hot }} \cdot \eta_{R C, \text { hot }}}$

$\begin{aligned} R & =\left(\frac{\left(1-\frac{T_{a i r}-\Delta T}{T_{\text {waste }}}\right)}{1-g\left(1-\frac{T_{a i r}-\Delta T}{T_{\text {waste }}}\right)}\right) \\ & \times\left(\frac{T_{\text {air }}-\Delta T}{\Delta T}\right) \cdot \frac{1}{\left(\frac{T_{\text {waste }}+\Delta T}{\Delta T}\right)\left(\left(1-\frac{T_{\text {air }}}{T_{\text {waste }}+\Delta T}\right)\right.}\end{aligned}$

$R=\left(\frac{\left(\frac{T_{\text {waste }}-T_{\text {air }}+\Delta T}{T_{\text {waste }}}\right)}{\frac{T_{\text {waste }}-g\left(T_{\text {waste }}-T_{\text {air }}+\Delta T\right)}{T_{\text {waste }}}}\right)$

$\times\left(\frac{T_{\text {air }}-\Delta T}{\Delta T}\right) \cdot \frac{1}{\left(\frac{T_{\text {waste }}+\Delta T}{\Delta T}\right)\left(\left(\frac{T_{\text {waste }}+\Delta T-T_{\text {air }}}{T_{\text {waste }}+\Delta T}\right)\right.}$

$R=\left(\frac{T_{\text {waste }}-T_{\text {air }}+\Delta T}{T_{\text {waste }}-g\left(T_{\text {waste }}-T_{\text {air }}+\Delta T\right)}\right)\left(\frac{T_{\text {air }}-\Delta T}{T_{\text {waste }}+\Delta T-T_{\text {air }}}\right)$.

$R=\frac{P 2 P_{\text {cold }}}{P 2 P_{\text {hot }}}=\left(\frac{\left(T_{\text {air }}-\Delta T\right)}{T_{\text {waste }}-g\left(T_{\text {waste }}-T_{\text {air }}+\Delta T\right)}\right)$

\subsection{Constant efficiency model}

The main inputs are the waste heat and air temperatures. Three parameters are varied to optimize the performance, namely the working fluid, the Reynolds ratio and the glide temperature (Table 1). The pump isentropic efficiency is computed with Eq. (12). $\eta_{p p, i s}=\frac{\dot{V}\left(P_{p p, e x}-P_{p p, s u}\right)}{\dot{W}_{p p, e l}}$

The compressor isentropic efficiency is defined by Eq. (13).

$\eta_{c m p, i s}=\frac{\dot{m}\left(h_{c m p, e x, i s}-h_{c m p, s u}\right)}{\dot{W}_{c m p, e l}}$

The expander isentropic efficiency is evaluated with Eq. (14).

$\eta_{\text {exp }, \text { is }}=\frac{\dot{W}_{\text {exp }, e l}}{\dot{m}\left(h_{\text {exp }, \text { su }}-h_{\text {exp }, \text { ex }, \text { is }}\right)}$

The value of the pinch point needs to be very low. Indeed a $1 \mathrm{~K}$ increase of this parameter leads to a P2P drop of 3\%. This means that heat exchangers should be oversized compared to a classical application in order to reach decent efficiencies. This model is power-independent. Practically, a nominal flow of $1 \mathrm{~kg} / \mathrm{s}$ is adopted for the heat pump since the flow (or power) has no influence on the observed outputs (power, P2P, COP, RC efficiency). The ORC flow is directly given by the Reynolds ratio (Eq. (1)).

\subsection{Cost model}

The cost model for such a non-mature technology is difficult to assess. The methodology used in Ref. [4] for MW-scale systems is used. The cost of the reversible HP/ORC is assumed to be equal to $166 €$ per $\mathrm{kW}$, the cost of the electric motor generator is $64 €$ per $\mathrm{kW}$, the cost of other system components (piping, insulation, site, control ...) is estimated at $170 €$ per $\mathrm{kW}$. It takes into account the cost analysis of each component, final assembly, installation and commissioning. For the storage a cost of 17 EUR per $\mathrm{kWh}$ is assumed [4]. Among the available information on the next prototypes of Carnot battery, the storage size in $\mathrm{kWh}$ is usually five to ten times larger than the electrical power $(\mathrm{kW})[3,4]$. Joining all these pieces of information together, it means that the total price is comprised between $485 € / \mathrm{kW}$ and $570 € / \mathrm{kW}$ and $57 € / \mathrm{kWh}$ and $97 € /$ kWh.

\section{Results}

This section aims at understanding how the inputs and 
Table 1

Value of the parameters for the constant efficiency model.

\begin{tabular}{|c|c|c|}
\hline & Parameter & Value \\
\hline \multirow[t]{8}{*}{ Inputs } & Evaporator pinch point $[\mathrm{K}]$ & 2 \\
\hline & Condenser pinch point $[\mathrm{K}]$ & 2 \\
\hline & Compressor isentropic efficiency [\%] & 75 \\
\hline & Sub-cooling $[\mathrm{K}]$ & 5 \\
\hline & Superheating [K] & 5 \\
\hline & Pump isentropic efficiency [\%] & 50 \\
\hline & Storage & Ideal (Plug-flow) \\
\hline & Pressure drop (exchangers) [bar] & 0.2 \\
\hline \multirow[t]{5}{*}{ Parameters } & $\begin{array}{l}\text { Evaporator/condenser glide (secondary } \\
\text { fluid) }[\mathrm{K}]\end{array}$ & {$[5-70]$} \\
\hline & Waste heat temperature $\left[{ }^{\circ} \mathrm{C}\right]$ & {$[30-100]$} \\
\hline & Air temperature $\left[{ }^{\circ} \mathrm{C}\right]$ & {$[0: 40]$} \\
\hline & Fluids & $\begin{array}{l}\text { Toluene, R1233zd(E), R1234yf, R11, Ammonia, R123, R141b, R142b, R123,R236EA,R245fa, SES36, R365MFC, } \\
\text { Isobutane, Ethanol, Water }\end{array}$ \\
\hline & Reynolds ratio (Eq. (1)) & {$[1: 3]$} \\
\hline
\end{tabular}

parameters of the system influence the performance of the system by using the model described in the section Methodology.

\subsection{Analytical model}

From the analytical model, two main results are highlighted. Firstly, the global performance of the system is always better with high waste heat temperature and low air temperature (Eqs. (7) and (8)). Also, the ratio between the cold and the hot P2P (Eq. (11)) is always below one since the lift, $\Delta \mathrm{T}$ (assumed equal for hot and cold storage) is larger than 0 and $g$ is by definition comprised between 0 and 1 . This model is very simple and allows to evaluate the performance of a TIPTES with only three inputs. It can be useful for prestudies of a given application. Nevertheless, this model requires several hypotheses (mainly the $g$ value) and a constant efficiency model is necessary for a more accurate description of the process.

\subsection{Constant efficiency model}

Performance is simulated for 16 classical working fluids (see Table 1) with Coolprop. The performance is illustrated with fluid $\mathrm{R} 1233 \mathrm{zd}(\mathrm{E})$. Results with other fluids are given in the appendices.

\subsubsection{Influence of the glide}

The influence of the glide temperature is depicted in Fig. 5. In

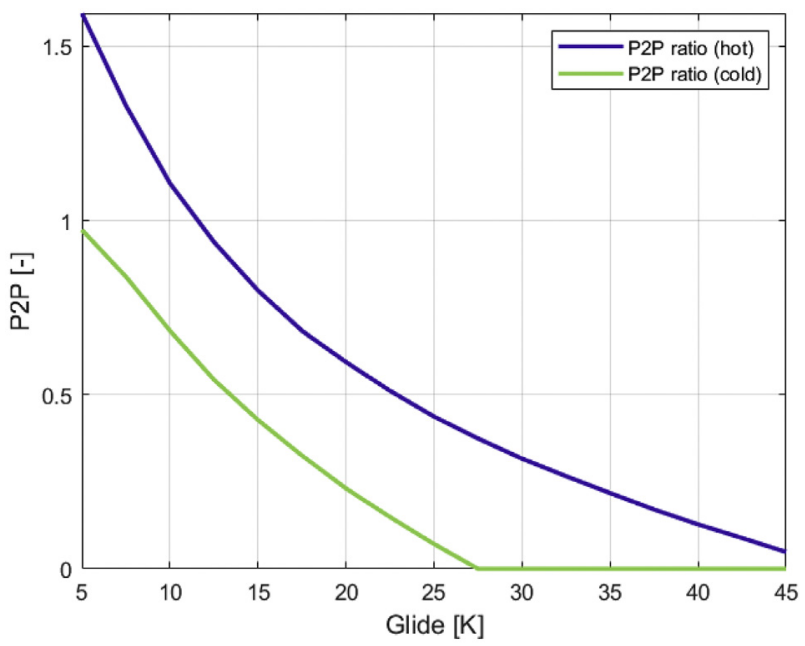

Fig. 5. Influence of the glide on the $\mathrm{P} 2 \mathrm{P}$ for the hot and cold storage layouts (R1233zd(E)). this example, the P2P is computed with a waste heat temperature of $75^{\circ} \mathrm{C}$ and an air temperature of $15^{\circ} \mathrm{C}$.

From Fig. 5, it appears that the hot storage configuration presents a higher P2P than the cold one. This observation is generalized in the next section. Also, the temperature glide needs to be limited to values below $15 \mathrm{~K}$ to keep a decent P2P. This constraint limits the compactness of sensible storage (see section compactness). In the whole paper, the glide is fixed to $10 \mathrm{~K}$ which is a decent compromise between performance and compactness. For the sake of completeness, mappings with $5 \mathrm{~K}$ and $15 \mathrm{~K}$ are also proposed in (Fig. 7 and Fig. 8).

\subsubsection{Compactness}

Before going further, it is important to quantify the energy density of such a technology. It is assumed that the volume of the heat pump and Rankine cycle are negligible compared to the size of the TES. The electrical energy for a given volume of storage can be computed through the product of the RC efficiency and the energy available in the TES for the hot storage configuration under sensible (water in this case) or latent form $(200 \mathrm{~J} / \mathrm{g})$. The energy density is directly related to the Reynolds ratio. High values of Reynolds ratio (up to 3 ) leads to higher compactness of the system (because of the increase of thermal power for the same machine) but can rise performance problems (as mentioned before). A value of one for the Reynolds ratio ensure a perfect matching of the components of the reversible HP/RC unit. As an example, the influence of the Reynolds on the compactness is plotted in Fig. 6. From this Figure, it appears that the phase change materials are promising here due to the low glide ( $5 \mathrm{~K}$ in this example with a pinch point of $2 \mathrm{~K}$ ). Also, the compactness is highly affected by the working conditions, the design and the layout of the considered system. In the next part of the paper, a Reynolds ratio of one is considered to ensure an optimal performance.

\subsubsection{Optimal fluid}

The fluid presenting the highest P2P is presented in Fig. 7 for different lift and different temperature levels. Generally, only 5 fluids show a decent efficiency among the 16 fluids from Table 1 : R1233zd(e), R1234yf, R11, R236ea and R245fa. From Fig. 7, fluids R1234yf and R1233zd(e) show better performance for low temperature differences between waste heat temperature and air temperature. Fluids R245fa and R11 are more suited for larger temperature differences. The P2P for each fluid and each lift are given in appendices. A comparison between the different fluids show that the differences are rather small between the 5 optimal fluids from Fig. 7. In conclusion, it means that those 5 fluids are probably the best candidates for an application with the considered 
Hot storage

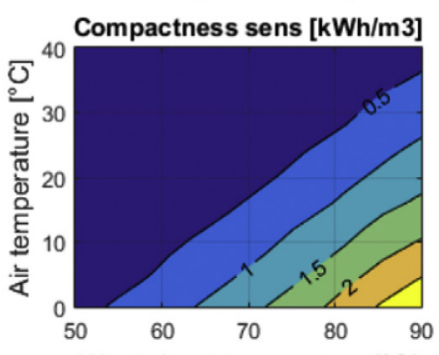

Waste heat temperature $\left[{ }^{\circ} \mathrm{C}\right]$

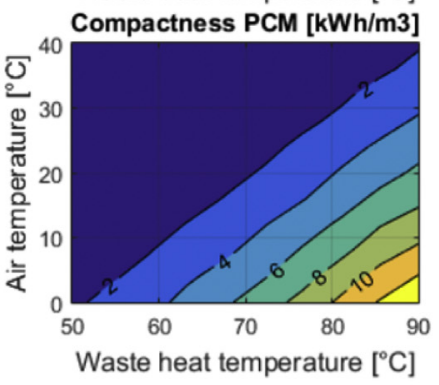

Cold storage

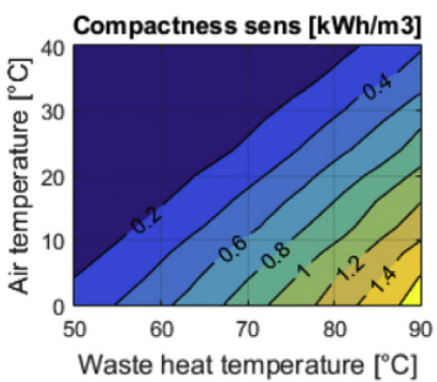

Compactness PCM [kWh/m3]

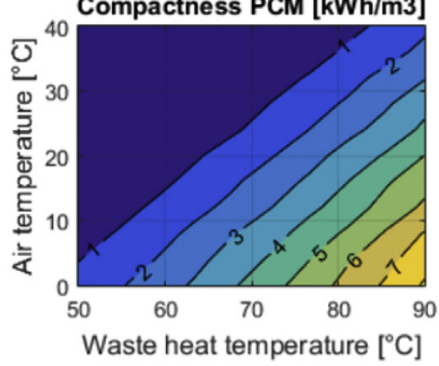

Hot storage

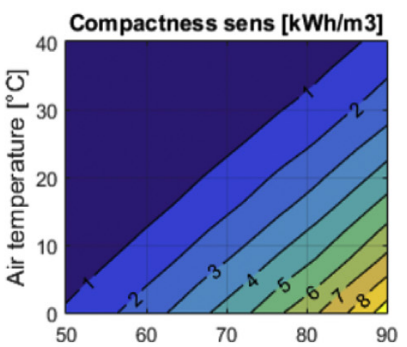

Waste heat temperature $\left[{ }^{\circ} \mathrm{C}\right]$

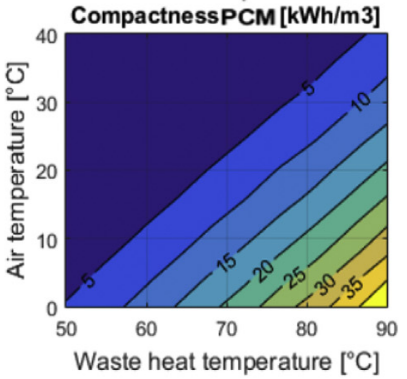

\section{Cold storage}

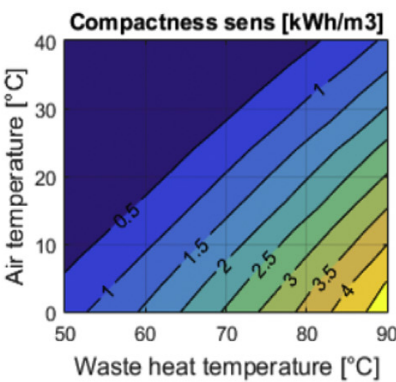

Compactness PCM [kWh/m3]

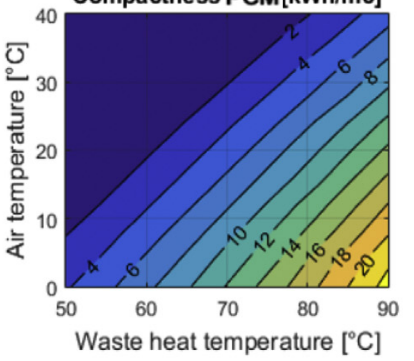

Fig. 6. Compactness of the systems (left) Reynolds ratio $=1$, (right) Reynolds ratio $=3$ (R1233zd(E)).

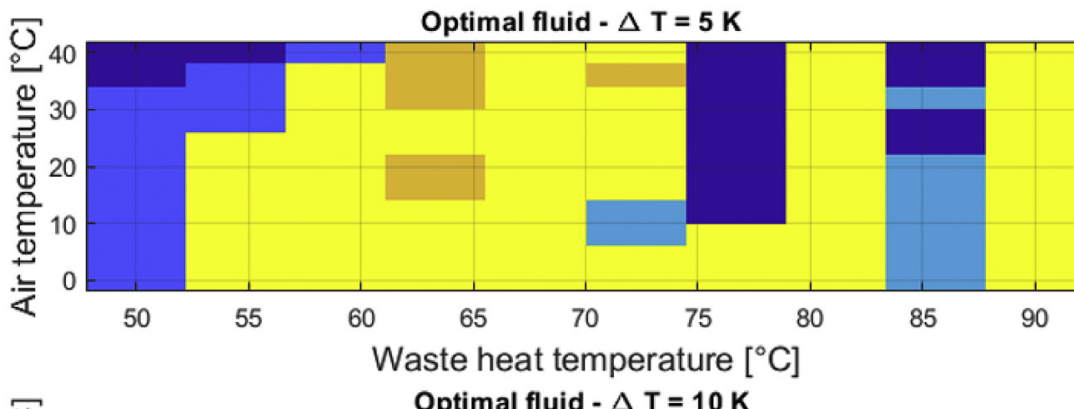

\begin{tabular}{|l|}
\hline R1233ZD(E) \\
$\square$ R1234YF \\
$\square$ R236EA \\
$\square$ R11 \\
$\square$ R245FA \\
\hline
\end{tabular}

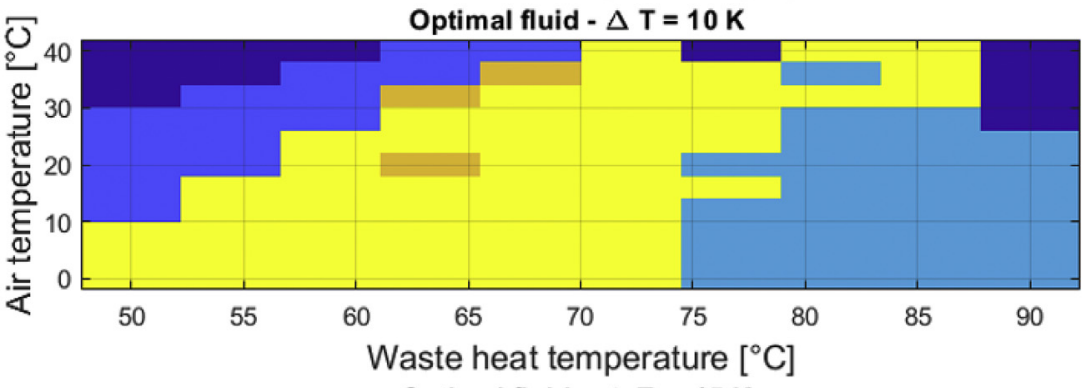

Optimal fluid $-\Delta \mathrm{T}=15 \mathrm{~K}$

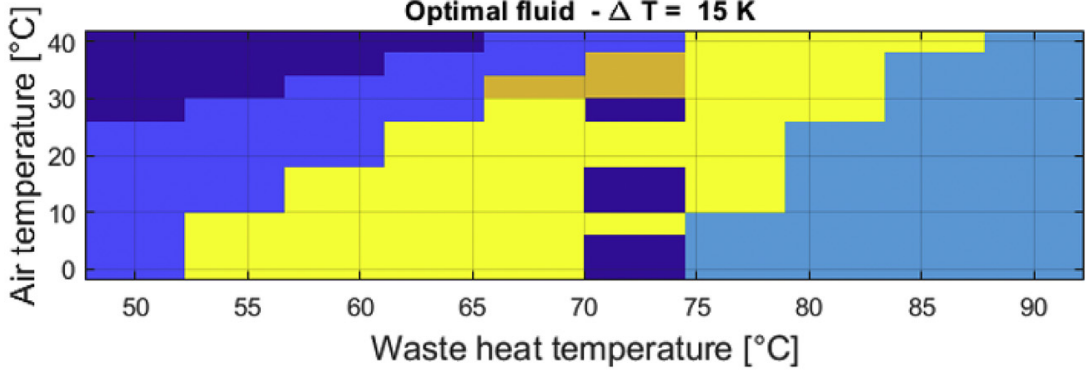

Fig. 7. Optimal working fluid for different configurations.

range of temperature. However, a dedicated accurate modeling should be considered to select the optimal one for a given case study.
3.2.4. Mappings of performance

A general mapping of performance is evaluated with a glide of $10 \mathrm{~K}(\mathrm{R} 1233 \mathrm{zd}(\mathrm{e}))$ for both hot and cold storages for a wide range of air and waste heat temperatures (Fig. 8). First, the RC efficiency 
$\underline{\text { Hot storage }}$
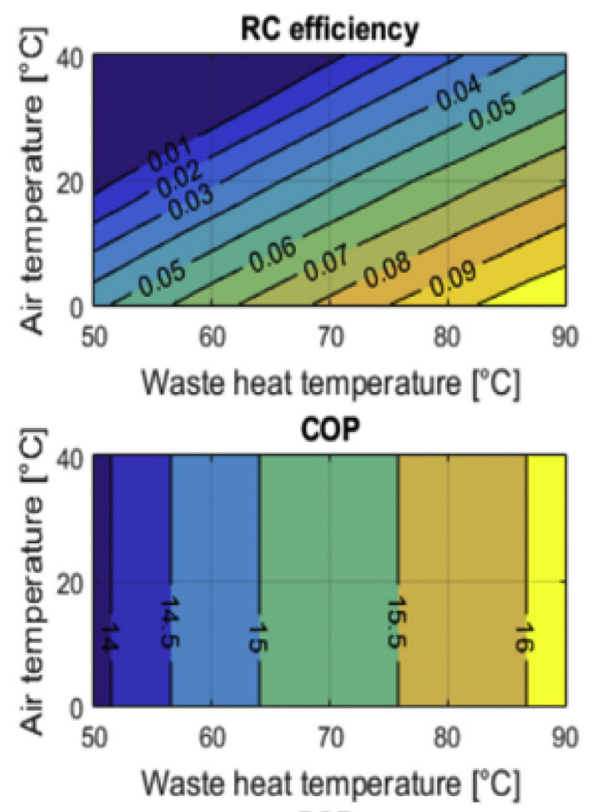

P2P

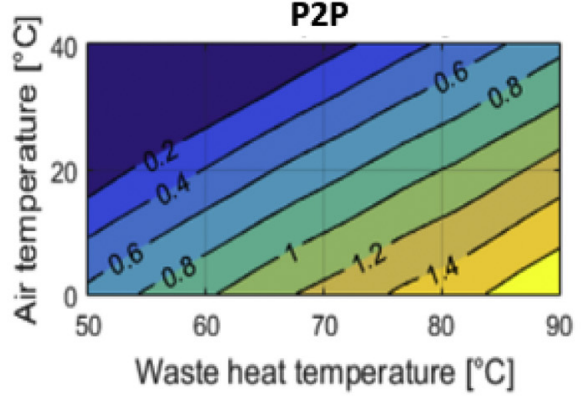

\section{Cold storage}
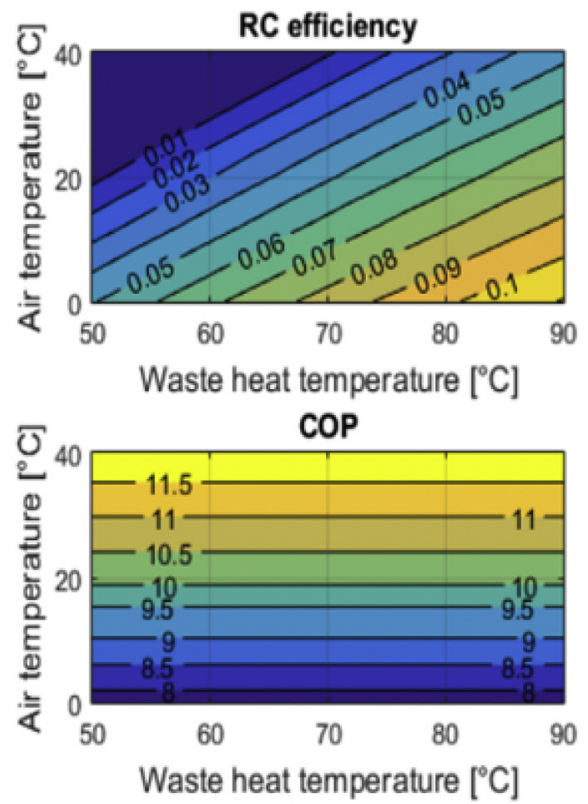

P2P

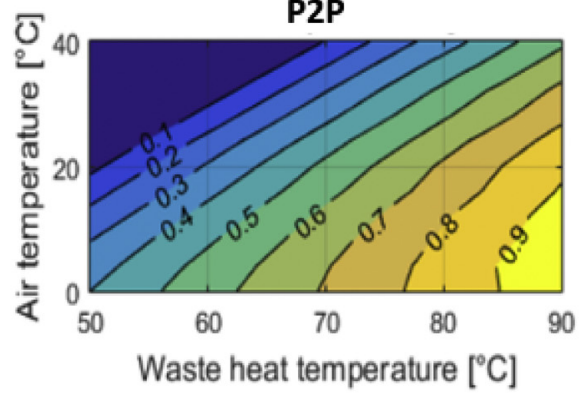

Fig. 8. RC efficiency, COP of HP and P2P as a function of the air temperature and the waste heat temperature (glide $=10 \mathrm{~K}, \mathrm{R} 1233 \mathrm{ZD}(\mathrm{E}))$.

naturally increases with the increase of the waste heat temperature and the decrease of the air temperature. The RC efficiency in the case of the cold storage is slightly higher due to the lower cold source temperature. The COP of the HP in the hot storage configuration is naturally independent of the air temperature and increases slightly with the waste heat temperature. For the cold storage layout, the COP of the heat pump is independent of the waste heat temperature and slightly increases with the air temperature within the inputs of this paper. Globally, the COP is rather constant due to the constant glide. This leads to a trend for the P2P which is similar to the RC efficiency: it increases with the waste heat temperature and decreases with the air temperature. Values with P2P larger than one can be obtained for a given range of conditions. As already mentioned, the hot storage configuration outperforms the cold storage layout whatever the inputs and parameters. This is due to two facts. First, a simple analytical solution shows the highest efficiency of the hot storage layout. Secondly, the Reynolds ratio is more restrictive for the cold storage layout due to highest difference between the heat pump and RC operating conditions (very different flows for the same thermal power). This means that it could be profitable to use two separate cycles (one separate HP and one separate RC) instead of a reversible system in this case. The influence of the glide is highlighted in Fig. 9 and Fig. 10, where the performance of the cycle is evaluated for values of $5 \mathrm{~K}$ and $15 \mathrm{~K}$.

\subsection{Comparison with competitive technologies}

Now that energy density numbers have been computed in the results section, it is possible to develop a complete comparison of the Carnot battery with other competitive technologies. This comparison is primarily interested in storage technologies that have a shifting capability of one day at least and the possibility to be efficient at large scale (up to MW), with characteristics such as high P2P, high energy density, low specific price, long lifetime. Different technologies are available in the considered range of requirements: pumped hydro-storage (PHS), fuel cells combined with hydrogen storage (FC), batteries (and flow batteries) (B), compressed air energy storage (CAES), liquid air energy storage (LAES), gravity energy storage (GES). PHS is the most widespread large-scale energy storage technology. The operating principle of PHS is to pump a fluid to a reservoir with a certain elevation when the electricity demand is low. In discharging mode, the fluid converts its potential energy in a turbine to produce electricity. CAES has also been demonstrated at large scale. In CAES, air is compressed in a given hermetic tank or underground reservoir during the charging mode and expanded in the discharge mode. However, they both require specific geological conditions [9], which significantly decreases the availability of these types of energy storages. Also, their energy density is rather low (see Table 2). Flow batteries could possibly become a useful way of storing large quantities of energy due to their large energy density $\left(60 \mathrm{kWh} / \mathrm{m}^{3}\right)$. However, they suffer from 
$\underline{\text { Hot storage }}$
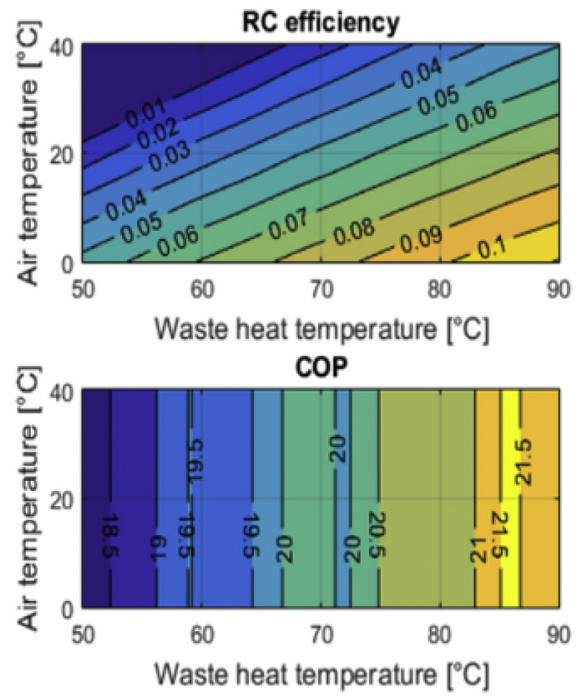

P2P

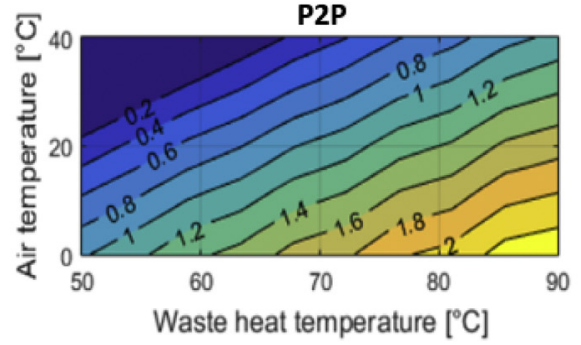

Cold storage

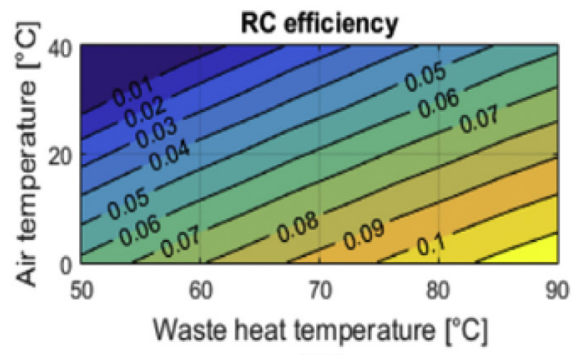

COP

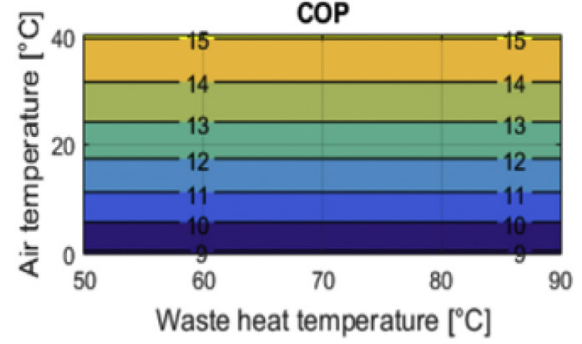

P2P

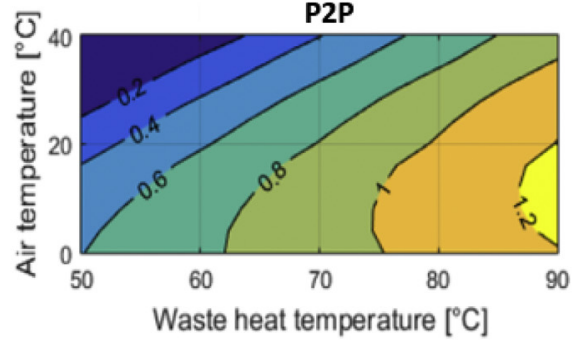

Fig. 9. ORC efficiency, COP of HP and P2P as a function of the air temperature and the waste heat temperature (glide $=5 \mathrm{~K}$, fluid $=\mathrm{R} 1233 \mathrm{ZD}(\mathrm{E})$ ).

a rather low lifetime and the use of rare (or expensive) materials (Table 2).

LAES (air compression to store it in its liquid state) and GES (potential energy store by moving a large mass vertically) are not mature technologies and suffer from large energy price and low energy density. Finally, the fuel cells, despite their high energy density (Table 2) present a relatively low lifetime with a limitation on the number of cycles.

This short summary of storage technologies with a storage period longer than a few hours shows the interest to develop and to evaluate new energy storage technologies such as the pumped thermal energy storage (PTES). The PTES technology is interesting due to its long cycle life, no geographical limitations, no need of fossil fuel streams and capability of being integrated into conventional fossil-fueled power plants or with any other type of waste heat source (Benato et al., 2018). As demonstrated in this paper, this type of storage is more beneficial using a waste heat source (Thermally Integrated Pumped Thermal Energy Storage) with higher P2P. The values provided in Table 2 are based on real data for the mature technologies (CAES, PHS, FC, B) but should be confirmed by experimental campaigns to validate them for the other types of storages.

The PTES technology should therefore be investigated with a focus on the development of a prototype demonstrating the high efficiency and the reliability of the system and of the TES storages, which need to be compact and cheap. This should help bringing the technology to the market.

\section{Conclusion}

This paper aims at evaluating the potential of the Pumped
Thermal Energy Storage compared to competitive technologies. First, a review of literature shows the low P2P of classical PTES $(<60 \%)$. However, recently a new thermally integrated PTES using a hot storage has been investigated showing high P2P. This paper aims at developing mappings of performance for this system but also for an innovative concept consisting in a thermally integrated PTES using a cold storage. A constant-efficiency model is developed and leads to the following conclusions:

- The higher the lift of the heat pump, the lower the P2P. This means that the energy storage temperature should preferably be close to the air temperature in the case of the cold storage configuration and close to the waste heat temperature in the case of the hot storage configuration. This observation is only valid for Thermally Integrated PTES. The classical PTES P2P is theoretically independent of the TES temperature.

- The results show a large zone on the operating map with high $\mathrm{P} 2 \mathrm{P}$, which makes the thermally integrated PTES technology very promising compared to other storage technologies despite the lower maturity.

- Among the 16 studied fluids, only 5 (R1233zd(e), R1234yf, R11, R236ea and R245fa) are presenting high performance and should be considered for this application.

- Mappings are provided to estimate which type of configuration (hot storage or cold storage) is more profitable depending on the glide, the waste heat temperature and the air temperature.

This work proves the theoretical encouraging performances of an innovative electrical energy storage. In the future, a complete economic analysis and a real proof of concept should be investigated to confirm these results. 

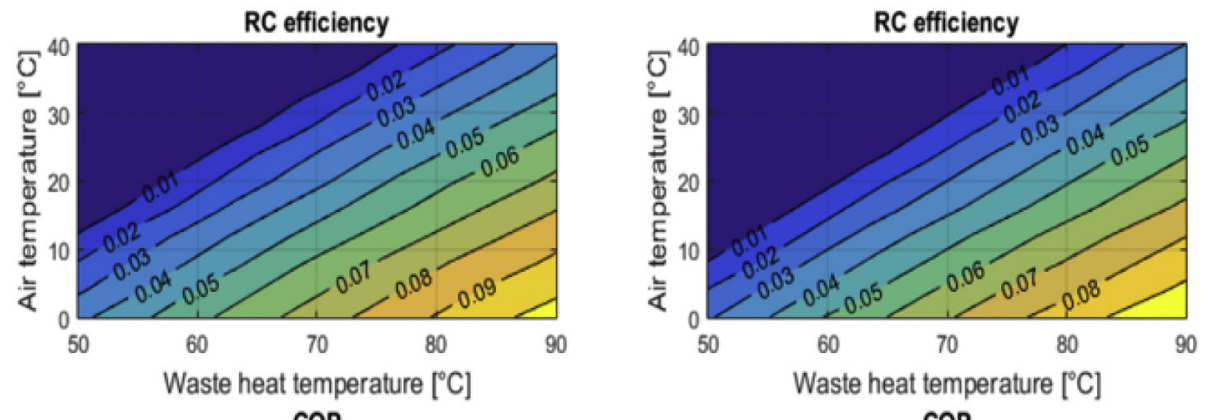

COP
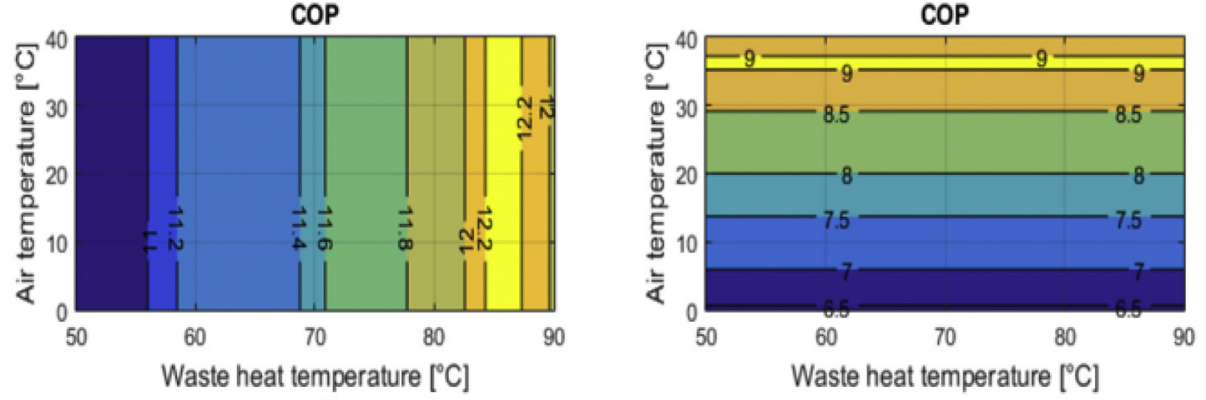

P2P

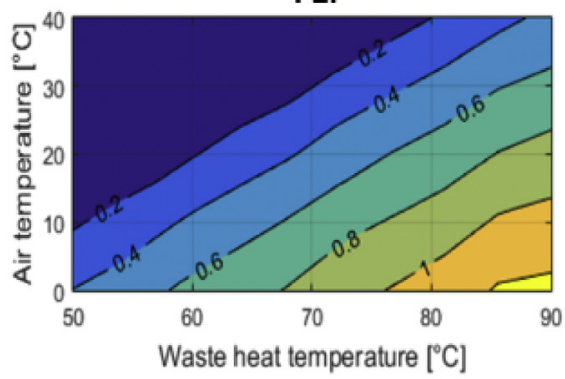

P2P

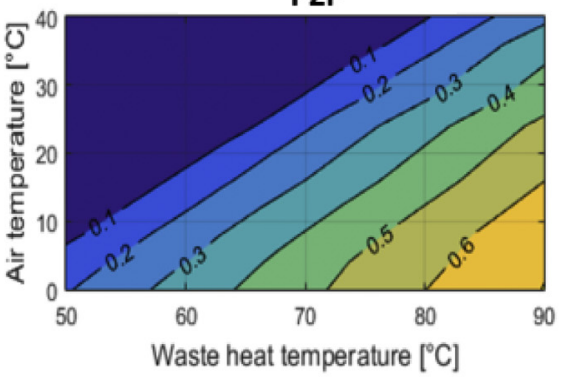

Fig. 10. ORC efficiency, COP of HP and P2P as a function of the air temperature and the waste heat temperature (glide $=15 \mathrm{~K}$, fluid $=\mathrm{R} 1233 \mathrm{ZD}(\mathrm{E})$ ).

Table 2

Comparison of the electrical energy storages [5,16-21].

\begin{tabular}{|c|c|c|c|c|c|c|c|}
\hline Technology & Energy density $\left[\mathrm{kWh} / \mathrm{m}^{3}\right]$ & Energy price $[\$ / \mathrm{kWh}]$ & Energy price $[\$ / \mathrm{kW}]$ & P2P [\%] & Lifetime [years] & Specific geographical conditions required & Year of publication \\
\hline PHS & $0.5-1.5$ & $5-100$ & {$[300-5200]$} & $65-87$ & $30-60$ & Yes & 2015 \\
\hline GES & $0.5-1.5$ & $\mathrm{~N} / \mathrm{A}$ & - & $70-86$ & $30-40$ & Yes & 2015 \\
\hline CAES & $3-12$ & $2-200$ & {$[400-2250]$} & $40-95$ & $20-60$ & Yes & 2015 \\
\hline LAES & 50 & $260-530$ & {$[500-3500]$} & $40-85$ & $20-40$ & No & 2015 \\
\hline Li-Ion B & 300 & $500-2500$ & {$[270-1500]$} & $85-95$ & $5-15$ & No & 2015 \\
\hline Flow B & $16-60$ & $120-1000$ & [175-10000] & $57-85$ & $5-15$ & No & 2015 \\
\hline FC & $500-3000$ & $1-10$ & [3500-10000] & $20-50$ & $5-30$ & No & 2015 \\
\hline PTES & $0.25-6.9$ & [62-107] & [533-627] & $70-80$ & $25-30$ & No & 2018 \\
\hline
\end{tabular}

This work proves the theoretical encouraging performances of an innovative electrical energy storage. In the future, a complete economic analysis and a real proof of concept should be investigated to confirm these results. Moreover, a part-load model should be developed to assess performance for real case studies.

\section{Credit author statement}

Olivier dumont did the modeling and the writing while vincent lemort worked on the analysis of the results and on the reviewing.

\section{Declaration of competing interest}

The authors declare that they have no known competing financial interests or personal relationships that could have appeared to influence the work reported in this paper.

\section{Nomenclature}

$\begin{array}{ll}\text { A } & \text { Area }\left(\mathrm{m}^{2}\right) \\ \text { B } & \text { Battery } \\ \text { CAES } & \text { Compressed Air Energy Storage } \\ \text { COP } & \text { Coefficient of performance }(-) \\ \text { Cmp } & \text { Compressor } \\ \text { Cp } & \text { Specific heat capacity }(\mathrm{J} /(\mathrm{kg} . \mathrm{K})) \\ \text { E } & \text { Electrical energy }(\mathrm{Wh}) \\ \text { Exp } & \text { Expander } \\ \text { Q } & \text { Thermal energy }(\mathrm{Wh}) \\ \text { FC } & \text { Fuel cell } \\ \text { g } & \text { Empirical coefficient }(-) \\ \text { GES } & \text { Gravity Energy Storage } \\ \text { HP } & \text { Heat Pump } \\ \text { L } & \text { Length }(\mathrm{m})\end{array}$




$\begin{array}{ll}\text { LAES } & \text { Liquid Air Energy Storage } \\ \dot{m} & \text { Mass flow rate }(\mathrm{kg} / \mathrm{s}) \\ \mathrm{P} & \text { Pressure }(\mathrm{Pa}) \\ \text { P2P } & \text { Power to Power ratio }(-) \\ \text { PHS } & \text { Pumped Hydro-storage } \\ \text { PTES } & \text { Pumped Thermal Energy Storage } \\ \mathrm{R} & \text { ratio }(-) \\ \mathrm{RC} & \text { Rankine Cycle } \\ \mathrm{Re} & \text { Reynolds }(-) \\ \mathrm{S} & \text { Speed }(\mathrm{m} / \mathrm{s}) \\ \text { TIPTES } & \text { Thermally Integrated PTES } \\ \mathrm{T} & \text { Temperature }(\mathrm{K}) \\ \dot{V} & \text { Volumetric flow }\left(\mathrm{m}^{3} / \mathrm{s}\right) \\ \dot{W} & \text { Power }(\mathrm{W}) \\ \eta & \text { Efficiency }(-) \\ \Delta & \text { Difference } \\ \nu & \text { Kinematic viscosity (Pa.s) } \\ \rho & \text { Density }(\mathrm{kg} / \mathrm{s})\end{array}$

\section{Subscript}

Air

Cd

El

Ev

Ex

HP

Is

pp

$\mathrm{RC}$

$\mathrm{Su}$

Waste

Outdoor air
Condenser
Electric
Evaporator
Exhaust
Heat pump
Isentropic
Pump
Rankine cycle
Supply
Waste heat recovery

\section{Appendix A. Supplementary data}

Supplementary data to this article can be found online at https://doi.org/10.1016/j.jeem.2020.102381.

\section{References}

[1] Chester website. 2019. consulted on the 01/02/2019, https://www.igte.unistuttgart.de/en/chair_hrt/research/current-projects/chester/index.html.

[2] Dumont O, Charalampidis A, Lemort V. Experimental investigation of a thermally integrated Carnot battery using a reversible heat pump/organic Rankine cycle. In: Proceedings of the refrigeration conference in Purdue 2020; 2020.

[3] Malta website. 2019. https://x.company/projects/malta/. consulted on the $01 /$ $02 / 2019$.

[4] Smallbone A, Jülch V, Wardle R, Roskilly A. Levelised cost of storage for pumped heat energy storage in comparison with other energy storage technologies. Energy Convers Manag 2019;152(15 November 2017):221-8.

[5] Benato A, Stoppato A. Pumped thermal electricity storage: a technology overview. Therm. Sci. Eng. Prog. 2018;6:301-15. https://doi.org/10.1016/ j.tsep.2018.01.017. June 2018.

[6] Jahnke A, Strenge L, Fleßner V, Wolf N, Jungnickel T, Ziegler F. First cycle simulations of the Honigmann process with $\mathrm{LiBr} / \mathrm{H} 2 \mathrm{O}$ and $\mathrm{NaOH} / \mathrm{H} 2 \mathrm{O}$ as working fluid pairs as a thermochemical energy storage. Int J Low Carbon Technol 2013;8:i55-61. 2013.

[7] Laughlin R. Pumped thermal grid storage with heat exchange. J Renew Sustain Energy 2017;9(2017):044103. https://doi.org/10.1063/1.4994054.

[8] Staub S, Bazan P, Braimakis K, Müller D, Regensburger C, Scharrer D, Schmitt B, Steger D, German R, Karellas S, Pruckner M, Schlücker E, Will S, Jürgen K. Reversible heat pump-organic Rankine cycle systems for the storage of renewable electricity. Energies 2018;11:1352. https://doi.org/10.3390/ en11061352. 2018.

[9] Dumont. Investigation of a heat pump reversible into an organic Rankine cycle and its application in the building sector. 2017 [PhD dissertation (Liège Belgium)].

[10] Quoilin S, Dumont O, Hansen K, Lemort V. Design, modeling, and performance optimization of a reversible heat pump/organic Rankine cycle system for domestic application. Trans ASME 011701-2 2016;138. JANUARY 2016.

[11] Dumont O, Quoilin S, Lemort V. Experimental investigation of a reversible heat pump/organic Rankine cycle unit designed to be coupled with a passive house to get a Net Zero Energy Building. Int J Refrig 2015;54:190-203.

[12] Frate G, Antonelli A, Desideri U. A novel Pumped Thermal Electricity Storage (PTES) system with thermal integration. Appl Therm Eng 2017;121:1051-8.

[13] Peterson R. A concept for storing utility-scale electrical energy in the form of latent heat. Energy 2011;36:6098e6109.

[14] AES. Active energy system website. https://www.activeenergysystems.com/ pumpedthermalenergystorage. consulted on the 10-10-2019.

[15] Dumont O. Investigation of a heat pump reversible in an organic Rankine cycle and its application in the building sector. 2017 [PhD dissertation, Liège (Belgium)].

[16] Díaz-González F, Sumper A, Gomis-Bellmunt O, Villafáfila-Robles R. A review of energy storage technologies for wind power applications. Renew Sustain Energy Rev 2016;16(4):2154-71. https://doi.org/10.1016/j.rser.2012.01.029.

[17] Aneke M, Wang M. Energy storage technologies and real life applications-a state of the art review. Appl Energy 2016;179:350-77. https://doi.org/ 10.1016/j.apenergy.2016.06.097.

[18] Chen H, Cong TN, Yang W, Tan C, Li Y, Ding Y. Progress in electrical energy storage system: a critical review. Prog Nat Sci 2009;19(3):291-312. https:// doi.org/10.1016/j.pnsc.2008.07.014.

[19] Gallo A, Simões-Moreira J, Costa H, Santos M, dos Santos EM. Energy storage in the energy transition context: a technology review. Renew Sustain Energy Rev 2016;65:800-22. https://doi.org/10.1016/j.rser.2016.07.028.

[20] White A, Parks G, Markides CN. Thermodynamic analysis of pumped thermal electricity storage. Appl Therm Eng 2013;53(2):291-8. https://doi.org/ 10.1016/j.applthermaleng.2012.03.030. 2013.

[21] Zakeri B, Syri S. Electrical energy storage systems: a comparative life cycle cost analysis. Renew Sustain Energy Rev 2015;2015(42):569-96. 